\title{
Agência e discricionariedade na prática policial
}

\section{Agency and discretion in police practice}

\author{
Maria do Carmo Leite de Oliveira* \\ Pontifícia Universidade Católica do Rio de Janeiro \\ Rio de Janeiro, Rio de Janeiro / Brasil \\ Rony Caminiti Ron-Rén Junior ${ }^{* *}$ \\ Pontifícia Universidade Católica do Rio de Janeiro \\ Rio de Janeiro, Rio de Janeiro / Brasil
}

\begin{abstract}
RESUMO: O interesse na relação indivíduo-sociedade é marcado na teoria social pela diversidade na compreensão do papel da agência na ação humana. Neste trabalho, revisitamos a questão da agência em uma perspectiva aplicada. Pretendese examinar a agência na prática policial a partir da análise do discurso metaagentivo que emerge em uma narrativa de desacato produzida espontaneamente por um policial durante uma entrevista de pesquisa. Com base na análise, foi possível verificar que: (i) apesar da gama de escolhas possíveis de ação circunscritas pela lei e pelos contextos situados, costuma-se aplicar uma única rota de ação a todas as situações avaliadas como desacato; (ii) há um novo modelo de policial cujo caráter reflexivo e crítico se alinha ao modelo de proximidade que se vem tentando implementar nas políticas de segurança pública no Rio de Janeiro.
\end{abstract}

PALAVRAS-CHAVE: agência; discricionariedade; prática policial.

\begin{abstract}
The interest in the individual-society relationship is characterized in social theory by the diversity concerning the role of agency in human action. In this article, we revisit the issue of agency in an applied perspective. We aim to examine agency in police practice through the analysis of the meta-agentive discourse emerged in a narrative whose theme was the disrespect of a police officer during a research interview. The analysis shows that: (i) despite the range of possible choices of actions circumscribed by the law and the situated contexts, a single route of action is usually applied to all situations that are evaluated as disrespect; (ii) there is a new model of police officer whose reflexive and critical character is aligned with a model of community-oriented police that the government has been trying to implement in public security policies in Rio de Janeiro.
\end{abstract}

KEYWORDS: agency; discretion; police practice.

\footnotetext{
*mcleitedeoliveira@gmail.com

** ronyronren@gmail.com
} 


\section{Introdução}

A ação humana sempre esteve associada à noção de agência. Contudo, encontramos na teoria social um extenso debate sobre suas possíveis definições, bem como diferentes formas de entender a sua importância no âmbito da dicotomia indivíduo-sociedade.

No estruturalismo francês, por exemplo, que tem como foco a primazia da sociedade (ou do fato social, na nomenclatura durkheimiana) sobre o indivíduo, entende-se a ação individual como restringida pelas estruturas fixas da sociedade. Já os interacionistas simbólicos, como Goffman, e etnometodólogos, como Garfinkel, ressaltam o caráter reflexivo e criativo que os indivíduos possuem ao construírem a realidade social e agirem no mundo. Uma concepção intermediária foi proposta por Giddens (1984), a partir do conceito de estruturação. Segundo o autor, estrutura e ação estão interligadas, uma vez que as nossas ações moldam e são moldadas pela realidade social. Em outras palavras, nesse processo dual, as estruturas existentes em sociedade, comunidades e grupos foram moldadas pelas ações regulares e previsíveis dos indivíduos. Estes, por sua vez, só conseguem agir com base no vasto conhecimento socialmente estruturado que possuem. Até mesmo Foucault (1999, p. 91), a quem muitos creditam uma abordagem teórica que nulifica a agência, dizia que "onde há poder, há resistência".

A discussão sobre agência e estrutura torna-se especialmente produtiva quando pensamos não na sociedade como um todo, mas em instituições cuja liberdade de ação é altamente restringida. Um caso exemplar é o da Polícia Militar (PM). Como se sabe, a PM é um instrumento do Estado e, como tal, sua liberdade também reside nas mãos do Estado. Do mesmo modo, os membros do corpo militar são formados para obedecer às ordens - sensatas ou não - vindas de patentes superiores. Por outro lado, é facultado tanto à instituição policial quanto ao policial, "usar a discricionariedade sempre que limites efetivos ao seu poder deixam o policial livre para fazer escolhas entre possíveis rotas de ação ou inação" (KENNETH, 1969 apud KLOCKARS, 1985, p. 93).

A questão que se coloca aqui é: até que ponto a formação policial cria condições para o desenvolvimento da capacidade de exercer o princípio da discricionariedade? Os desafios encontrados pelos policiais na prática cotidiana mostram como é difícil lidar com uma miríade de situações não previstas nos manuais, diretrizes e notas de instrução. Somem-se a isso as inúmeras circunstâncias em que a abertura da lei permite que o policial tome decisões amparadas no que considera relevante. Esse poder policial 
de discricionariedade oportuniza uma agência que se constrói a cada situação imposta, a partir de contextos situados e possibilidades decisórias contingentes a eles (MUNIZ, 1999, 2008; PONCIONI, 2005). Não só nesses contextos há desafios. Há situações em que o regulamento é claro como o do uso progressivo da força - mas o que se observa é que os policiais não usam sua subjetividade para exercer a discricionariedade nesses casos.

Neste trabalho, propomo-nos contribuir para o estudo do papel da agência do indivíduo na prática profissional do policial. Os dados consistem na narrativa de um caso tipicamente enquadrado como de desacato a autoridade. A narrativa foi produzida espontaneamente por um policial militar do estado do Rio de Janeiro, atuante no programa de Unidade de Polícia Pacificadora (UPP), durante uma entrevista de pesquisa.

O objetivo deste trabalho é examinar a questão da agência na prática policial a partir da análise do discurso meta-agentivo que emerge em sua fala. Entendemos discurso meta-agentivo como aquele definido por Ahearn (2010, p. 41), "no qual a agência é, de alguma forma, o tópico da conversa, isto é, quando as pessoas falam sobre suas próprias ações e a dos outros, quando atribuem responsabilidades pelos eventos, e como descrevem seus processos de tomada de decisões e de terceiros".

\section{Agência na/pela linguagem}

O interesse das ciências sociais pelas questões de agência é relativamente recente. Ahearn (2010) destaca duas possíveis razões para a emergência de estudos que focalizam a agência: (i) os movimentos sociais ocorridos entre a década de 1960 e o início dos anos 1990, a partir dos quais muitos acadêmicos puderam testemunhar ou até mesmo participar de ações com vistas à transformação social; e (ii) as críticas pós-modernas e pósestruturalistas ao estruturalismo, que não levava em conta as ações dos indivíduos, e às narrativas mestras impessoais, sem tensões ou contradições por parte dos indivíduos e de coletivos.

Desde então, diversas definições de agência já foram propostas, sendo as de Ahearn (1999, 2001, 2010) e Duranti (2004) as mais conhecidas e utilizadas nos estudos da linguística sociocultural ${ }^{1}$. Ahearn (2010, p. 28) define agência

\footnotetext{
${ }^{1}$ Bucholtz e Hall (2005) cunham o termo para abarcar um campo que incorpora diferentes áreas que se interessam pelas interseções entre linguagem, cultura e sociedade, como a linguística antropológica, a análise da conversa, análise crítica do discurso, sociolinguística, entre outras.
} 
como "capacidade socioculturalmente mediada de agir". A breve definição é proposital, segundo a autora, pois não toma posições em diversas questões que geralmente perpassam uma definição de agência, como a intencionalidade das ações, consciência e níveis de agência (individual, supraindividual e subindividual). Embora Ahearn dê margem a uma ampla visão de agência com sua definição, a autora enfatiza que não podemos entendê-la como sinônimo de livre arbítrio, porque se ignoraria a natureza social da agência e a influência da cultura nas ações humanas; ou de resistência, por ser entendida como uma das formas possíveis de manifestação da agência, sendo a manutenção e o reforço do status quo também possíveis. Duranti (2004, p. 453) propõe sua definição de agência da seguinte maneira:

A agência é entendida como propriedade das entidades (i) que possuem algum grau de controle sobre seus comportamentos, (ii) cujas ações no mundo afetam outras entidades (e suas ações) e às vezes a si mesmas, (iii) cujas ações são objetos de avaliação (e.g. em termos de responsabilidade por um dado resultado da ação).

O autor explica que a propriedade (i) está intimamente ligada à noção de intencionalidade e também às outras propriedades, como poder (implícito na segunda propriedade) e avaliação (terceira propriedade). Já a propriedade (ii) envolve uma corrente causativa, na qual as ações dos sujeitos afetam outros e a si mesmos, restando a propriedade (iii), ligada aos conceitos de moralidade e de performance.

Além da definição explicitada, Duranti (2004) propõe duas dimensões como constitutivas da agência na linguagem: a performance e a codificação. Apesar da divisão didática, as duas dimensões são mutuamente constitutivas, pois a performance depende e afeta a codificação que, por sua vez, sempre serve a propósitos performativos.

$\mathrm{O}$ autor também entende que qualquer ato de fala envolve algum tipo de agência, independentemente das intenções do falante e do interesse ou colaboração do ouvinte, pois ao falarmos criamos uma realidade com potencial de afetar todos que porventura estejam ouvindo. Ele também propõe algumas generalizações sobre a relação agência e linguagem, dentre elas, a de que todas as línguas possuem formas de representar agência e que tais formas variam não só entre diferentes línguas, mas inclusive em uma mesma língua. Por último, propõe que todas as línguas possuem instrumentos de mitigação da agência, a partir de diversas estratégias gramaticais e discursivas. 
Apesar de entendimentos, nomenclaturas e definições diversas, entendemos, assim como Bucholtz e Hall (2005), que as interações discursivas, por um lado, constituem as estruturas sociais e, por outro, são constituídas de construtos materiais e ideológicos que produzem relações de poder. Dentro da discussão sobre o papel de estrutura social e ação humana, nos alinhamos a Ahearn (2010), que propõe que entendamos os indivíduos como "frouxamente estruturados".

A autora também destaca que estudar a linguagem é uma boa maneira de entender melhor as formas pelas quais as pessoas reproduzem e transformam as estruturas sociais e sugere três perspectivas interrelacionadas como modo de analisar a relação entre agência e linguagem. A primeira seria o estudo da estrutura linguística em si, na qual a agência é codificada e moldada. A segunda, o estudo dos processos sócio-históricos, entendendo a agência dentro de um contexto macro e mais sociológico que linguístico. Por último, o estudo do discurso, tanto em nível micro, com a análise da interação, quanto em um sentido mais amplo, como a visão de discurso foucaultiana como forma de poder ao qual estamos subordinados.

\section{Metodologia}

Os dados da pesquisa foram gerados a partir de entrevista semiestruturada (FONTANA; FREY, 2005), realizada no começo de 2016 em uma base de Unidade de Polícia Pacificadora (UPP), na capital do estado do Rio de Janeiro. A entrevista, que durou cerca de 94 minutos, buscava entender como o policial lidava com os hiatos deixados por sua formação em sua prática profissional e com os desafios de um modelo de policiamento que não tinha como foco apenas o cumprimento da lei, mas também a construção de uma relação de proximidade com o cidadão. Uma das sequências que chamou nossa atenção nessa entrevista foi uma narrativa sobre um evento de desacato, produzida espontaneamente pelo entrevistado, após uma das entrevistadoras problematizar, com base na geração de dados de uma outra pesquisa desenvolvida no projeto de pesquisa Expertise Interacional de Práticas Profissionais (VELASCO, 2014; VELASCO; OLIVEIRA, 2016) o modo como os policiais aplicam o conceito de desacato a autoridade.

Nossa atenção se justificava em função não só da habilidade narrativa do entrevistado, mas também do ponto dessa narrativa (LABOV, 1972), isto é, da razão pela qual a história estava sendo contada, sua mensagem principal: a defesa de um modelo de agir policial orientado por uma tomada de decisão 
consciente, crítica e humana. Com base nesse primeiro entendimento, identificamos dois momentos da narrativa em que a agência tinha um papel fundamental: o primeiro tem como foco a ação policial no controle de um ambulante que tentava, irregularmente, comercializar produtos dentro de um dos modais de transporte público ${ }^{2}$. O segundo tem como foco a aplicação do conceito de desacato diante da reação desse mesmo vendedor à tentativa dos policiais de reterem suas mercadorias. Em ambos os momentos o entrevistado contrasta - explicitamente ou implicitamente - modelos de policial em termos do uso da liberdade de escolha de uma rota de ação, sem ferir as normas, o regulamento.

Por motivos de segurança e por compromisso assumido de manutenção de anonimato do entrevistado, informações sobre o universo da pesquisa precisam ser limitadas. Contudo, podemos dizer que o entrevistado, Almir (nome fictício), possui ensino superior completo em Direito e à época da entrevista era cabo da Polícia Militar do Rio de Janeiro. Em termos de experiência, ele estava em sua segunda UPP e já atuava há cinco anos nesse contexto. Como policial de proximidade ${ }^{3}$, Almir exercia a função de Relações Públicas, tendo também atuado como coordenador de atividades de policiamento de proximidade.

A narrativa selecionada foi transcrita com base no modelo utilizado pela Análise da Conversa ${ }^{4}$. Ressaltamos, em consonância com Gago (2002), e Garcez, Bulla e Loder (2014), que entendemos o processo de transcrição como atividade analítica. Por essa razão, assumimos que a transcrição nada mais é que uma representação (dentre tantas possíveis) da realidade, diferente do aqui e agora interacional entre os participantes da interação, e passível de problemas de representação geral.

\footnotetext{
${ }^{2}$ De acordo com o Decreto n. ${ }^{\circ} 29.881$, de 18 de setembro de 2008, Artigo 21, “é proibida a concessão e o remanejamento de autorização para a atividade do comércio ambulante: I - em frente a [...] parada de coletivo e outros locais inconvenientes; II - a menos de cinquenta metros de estação de embarque e desembarque de passageiro". Ademais, o Artigo 37 do Código Disciplinar do Serviço Público de Transporte de Passageiros por meio de Ônibus do Município do Rio de Janeiro também estabelece que "o Auxiliar de Transporte não deve permitir a prática de mendicância e a venda de objetos ou alimentos no interior do veículo".

${ }^{3}$ Neste artigo, entendemos por policial de proximidade aquele que atua no Grupamento de Polícia de Proximidade (GPP), o qual é responsável pela construção de laços de proximidade com a comunidade, através de diversas ações de cunho social. Cf. Menezes (2015) para as demais formas de atuação policial em contextos de UPP.
}

${ }^{4}$ Cf. anexo. 


\section{Agência e discricionariedade policial: o uso da força}

Uma das decisões que um policial deve tomar num evento de controle de um infrator diz respeito ao uso da força. Como previsto, o uso da força deve ser progressivo, isto é, ajustado ao nível de submissão ou resistência de quem está sendo detido. Um evento de desacato, por exemplo, exige o exercício do juízo discricionário por parte do policial quanto ao uso da força adequada a cada momento e quanto à decisão de conduzir ou não o acusado à delegacia.

A sequência da narrativa é aberta por um prefácio, no qual Almir nos conta que não concorda com o regulamento que proíbe a venda de produtos em transportes públicos. Essa avaliação aponta, por um lado, para um questionamento da propriedade da ação entendida como infração. Por outro lado, anuncia os limites da subjetividade do policial em sua prática. Como se prevê, apesar da crítica, infere-se que a lei será aplicada, como devido. O prefácio funciona como um resumo (LABOV, 1972), nos preparando para o relato de um caso de detenção de um "ambulante em transporte público".

EXCERTO 1

\begin{tabular}{|ll}
25 & Almir ai tava lá no brt e chama "prioridade \\
26 & prioridade" lá na frente (0.4) fomos correndo. \\
27 & chegou lá $(0.4)$ um cara-cara altamente (.) \\
28 & nervoso (.) batendo em todo mundo. e os \\
29 & policial-alguns policiais à paisana tentando \\
30 & sequrar ele ninguém consequia sequrar o cara \\
31 & "segura sequra ele"
\end{tabular}

A partir daí, Almir constrói sua narrativa tentando emular não só as sequências de eventos tal como elas teriam ocorrido, mas também seu conhecimento sobre o que estava ocorrendo naquele momento. Como veremos, isso é evidenciado a partir da categorização que faz do ambulante, não por sua atividade ou pela condição em que se encontra (pelo menos, suspeito). Ele o categoriza como "cara altamente (.) nervoso (.) batendo em todo mundo" (1. 27-28). Ao descrevê-lo como uma pessoa descontrolada, Almir traz uma percepção de contexto que é essencial para o exercício da discricionariedade quanto ao uso da força. 
EXCERTO 2

\begin{tabular}{|c|c|c|}
\hline 31 & A.1mix & ele veio pro meu lado eu falei "irma \\
\hline 32 & & encosta encosta" nå sabia $\circ$ que tava \\
\hline 33 & & acontecendo \\
\hline 34 & & ENCosta" (0.4) sem meter a mão na arma nem \\
\hline 35 & & nada $>0$ cara tava desarmado porque que eu<- \\
\hline 36 & & a arma é só pra defender mesmo cara você não \\
\hline 37 & & tom (0.3) que utilizar a arma >pogar a arma \\
\hline 38 & & e botar na mấ $(0.7)$ opo cara ${ }^{\circ}($.$) se eu$ \\
\hline 39 & & botar minha arma na mầ ela tá destravada \\
\hline 40 & & (1.1) se esse cara vem pra cima de mim (1.4) \\
\hline 41 & & e por acaso aperto o gatilho e mato o cara. \\
\hline 42 & & (1.2) tom noção do tamanho da merda que vai \\
\hline 43 & & dar? \\
\hline
\end{tabular}

Nesse excerto, Almir começa a relatar sua própria ação no evento. Por não saber àquela altura o que estava acontecendo, sua estratégia de controle do suspeito é apenas verbal. Com base no poder de sua autoridade, ele emite uma ordem que cresce em força ("irmão encosta encosta", 1. 31-32) através da mudança na qualidade da voz (ENCOSTA ENCOSTA ENCOSTA ENCOSTA, 1. 33). A partir daí, o policial indica opções de rota de ação que considera adequadas ou inadequadas. Embora a agência gramatical tenha sido apagada (sem meter a mão na arma nem nada, 1.34), ela é inferida (eu não meti a mão na arma), seguida da explicação de que o suspeito não estava armado.

Como se observa na sequência, o narrador suspende a narrativa na linha 35, para dar uma espécie de aula sobre uso de arma (1. 36 e 37), nos moldes descritos por Tannen e Wallat (2013), na análise de uma consulta pediátrica. A primeira instrução é a sobre as condições de uso da arma (é: só pra defender mesmo cara você não tem (0.3) que utilizar a arma $>$ pegar a arma e botar na mão<, 1. 35-37). Em seguida, uma narrativa hipotética (BAMBERG; GEORGAKOPOULOU, 2008; RIESSMAN, 1993) é introduzida para ilustrar as consequências do mau uso da arma (1. 39-42).

Em termos de agência, observa-se nesse excerto que Almir relata o que faz e o que poderia ter feito, mas decidiu não fazer diante das condições apresentadas. Embora a agência gramatical não esteja explícita, no próximo excerto já fica claro que Almir vai usar a agência gramatical para defender a visão de um modelo de policial que avalia o contexto, reflete sobre suas ações e escolhe a atuação mais adequada. 


\section{EXCERTO 3}

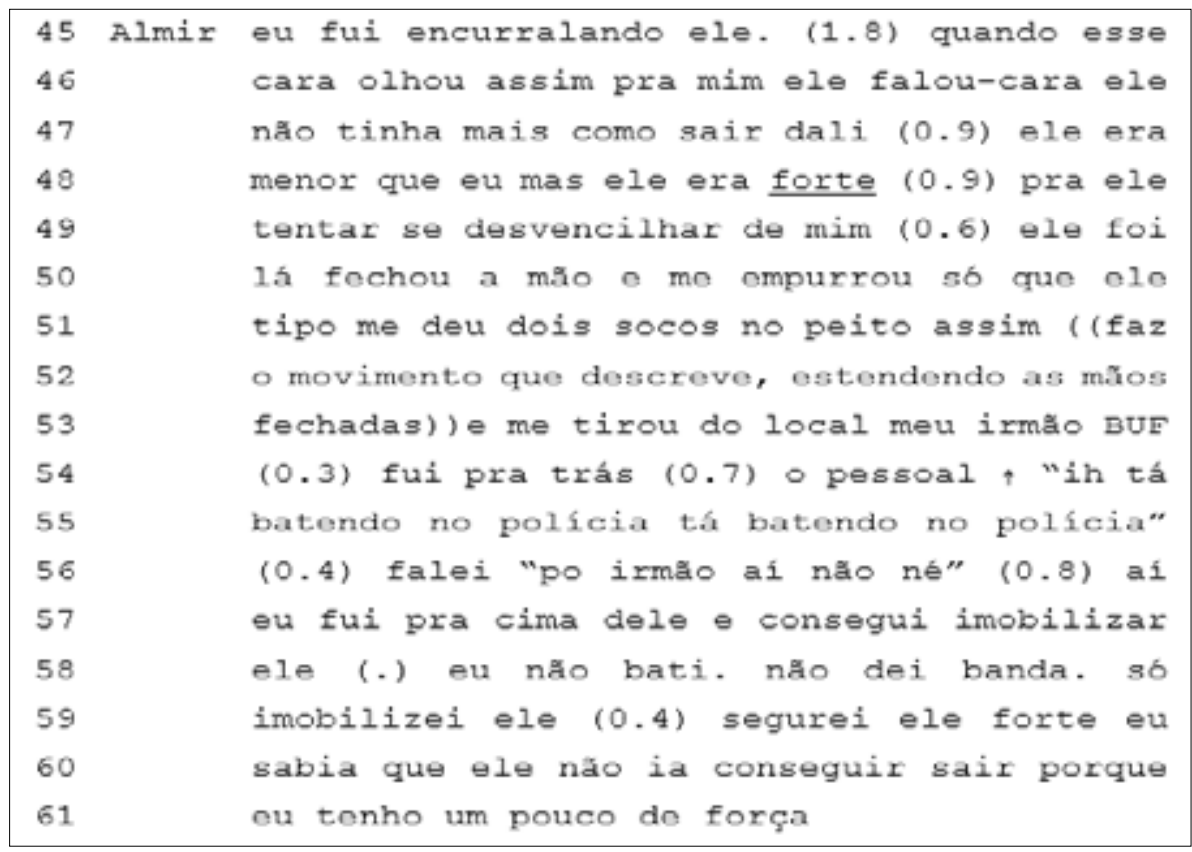

$\mathrm{Na}$ narrativa podemos perceber que há uma gradação em termos das ações exercidas por Almir para controlar o "cidadão descontrolado". Grosso modo, essa gradação acaba por corresponder aos modelos de uso progressivo da força ensinados nos cursos de formação policial (Quadro 1).

QUADRO 1 - Adaptação do modelo FLETC de uso da força

\begin{tabular}{|c|c|}
\hline AVALIAÇĀO POLICIAL & ESCOLHA POLICIAL \\
\hline $\begin{array}{l}\text { Resistência ativa } \\
\text { (agressão letal) }\end{array}$ & $\begin{array}{l}\text { Disparo da arma de fogo } \\
\text { Golpes de defesa em regiōes vitais }\end{array}$ \\
\hline $\begin{array}{l}\text { Resistência ativa } \\
\text { (agressão não letal) }\end{array}$ & $\begin{array}{r}\text { Uso dissuasivo da arma de fogo } \\
\text { Controle com instrumentos de menor } \\
\text { potencial ofensivo }\end{array}$ \\
\hline & Controle fisico \\
\hline Resistência passiva & Controles de contato \\
\hline \multirow[t]{2}{*}{ Cooperativo } & Verbalização \\
\hline & Presença policial \\
\hline ABORDADO & POLICIAL \\
\hline
\end{tabular}

Fonte: Betini e Duarte (2012) 
Ainda no excerto 2, tínhamos o uso da verbalização, quando o policial ordena repetidas vezes para que o ambulante encostasse (1. 32-33). Já no excerto 3, na linha 45, temos a primeira menção explícita de agência gramatical em um contexto não hipotético ("eu fui encurralando ele."). Almir se posiciona de forma a limitar as possibilidades de escape do vendedor que, por sua vez, resistia passivamente até então, isto é, sem demonstrar intenção de ferir o policial. O ato de resistência torna-se ativo a partir da linha 50, quando o policial descreve que foi empurrado com dois socos no peito. Essa ação acarreta uma reação, concretizada na linha 57 ("eu fui pra cima dele"), quando Almir exerce um controle físico a fim de imobilizá-lo.

Contudo, diferentemente das outras ações agentivas narradas pelo policial, o ato de imobilizar é mitigado a partir de diversos recursos. Primeiramente há o uso do discurso construído (TANNEN, 2007), quando Almir anima as vozes dos transeuntes (1.54-55) para relatar o que estava acontecendo naquele momento. É interessante perceber que Almir havia formulado a ação do vendedor, em um primeiro momento, como empurrão (1. 50), mas, ao construir a fala do público, realiza um autorreparo para a ação de bater, o que configura agressão. $O$ policial volta a utilizar o discurso construído na linha 56 ("po irmão aí não né"), como se falasse com o ambulante que o agrediu. Ao tornar relevante a fala dos transeuntes ( $\uparrow$ “ih tá batendo no polícia tá batendo no polícia", 1. 54-55), Almir demonstra o entendimento do público quanto às categorias de pertença (SACKS, 1992) em jogo naquele momento, bem como quanto às atividades que poderiam ou não estar atreladas a elas. Um civil ser responsável pela atividade "bater em um policial" é entendido como notavelmente reportável (LABOV, 1972), uma vez que destoa do conhecimento e raciocínio sobre estruturas sociais presentes no senso comum (WATSON, 1978), sendo, portanto, utilizado pelo policial como mais um argumento a fim de justificar o uso da força.

Além do autorreparo (empurrar - bater) em relação à ação do ambulante, Almir realiza outro autorreparo na descrição de sua ação de "imobilizar" para a produção "segurar forte" (1. 59). Há, portanto, uma intensificação da carga semântica de uso da força nas ações do vendedor, ao passo que as ações do policial são suavizadas. Esse mesmo recurso argumentativo é utilizado nas atribuições de força. Almir categoriza o vendedor como "forte" (1. 48), realçando o atributo a partir de ênfase prosódica, e mitiga sua força pelo uso do bedge "um pouco" ("um pouco de força", 1. 60-61). 
Além de mitigar sua agência ao imobilizar o vendedor, Almir também interrompe o fluxo da narrativa para, mais uma vez, ressaltar quais ações não estavam incluídas ao "ir para cima” do ambulante, isto é, não dar banda e não bater (1. 58). De forma semelhante ao account produzido no Excerto 1 sobre a importância de não utilizar a arma despropositadamente, o policial se coloca como agente não de uma ação, mas de uma inação que o projeta como um policial com práticas diferentes daquelas que circulam no senso comum.

Construir uma narrativa na qual o uso da força policial se faz presente é um trabalho delicado. Polícia e uso de força não costumam ser retratados pela sociedade sob uma lente positiva, visto a quantidade de relatos que chegam até nós sobre truculência policial e suas arbitrariedades no uso da força. O modelo de policial no senso comum é o do "tiro, porrada e bomba". É daquele que não respeita o cidadão abordado, porque o esculacha, porque dá banda. Contudo, no processo de construção da narrativa, há a tentativa de construção de outro modelo de policial: aquele que reflete sobre o contexto e usa a força de forma tática e profissional. Afinal, era essa nova concepção de policial um dos objetos de interesse da entrevista de pesquisa. Um dos recursos utilizados por Almir a fim de evidenciar o caráter técnico de seu fazer policial é a construção de uma agência de inação, na qual ressalta as rotas de ação que poderia ter tomado (notadamente atreladas a uma prática policial caracterizada no senso comum como de brutalidade), mas que intencionalmente não tomou.

A agência do policial é justificada pelo contexto da narrativa (RYMES, 1995). Almir deve agir, pois é seu dever como policial conter um "cara altamente nervoso batendo em todo mundo"; "ir pra cima dele" porque ele "estava batendo no polícia", o que evidencia o desrespeito à autoridade do policial e da instituição que ele representa. Além das justificativas apresentadas para o uso da força, Almir mitiga suas ações de controle físico do ambulante.

Um ponto importante a esclarecer é que a narrativa de Almir não ilustra a proposta apenas de um indivíduo. As pesquisas desenvolvidas no âmbito do projeto "Expertise interacional e práticas profissionais", produzido com o apoio do Conselho Nacional de Desenvolvimento Científico e Tecnológico (CNPq), ao qual os autores e outros pesquisadores se vinculam, mostram que Almir é apenas uma das vozes de um grupo de policiais que atuam em UPP e põem em prática um discurso alinhado a uma visão mais humanizada da polícia. 


\section{Agência e discricionariedade policial: a subjetividade na tomada de decisão}

A detenção por desacato geralmente é justificada pelos policiais nos casos em que o abordado grita, xinga, reage, enfim, resiste a submeter-se à autoridade do policial. De modo geral, os policiais não consideram as condições nas quais ocorrem o suposto ato de desacato. $\mathrm{O}$ fato de se verem como autoridade impede-os de reconhecer significados situados de desacato.

O Excerto 4 da narrativa ocorre após Almir ter relatado a imobilização do ambulante. Em linhas aqui suprimidas, Almir relata que somente após tê-lo contido soube que, na verdade, aquele "cara altamente nervoso batendo em todo mundo" era um vendedor de balas que teve todas as suas mercadorias apreendidas. Em seguida, em um discurso construído que anima as vozes dos outros policiais, Almir mostra como a operação padrão nesses casos seria a condução à delegacia. E como mostra o discurso construído, os policiais atribuem a Almir a responsabilidade do encaminhamento do ambulante à delegacia (1. 77 e 78).

\section{EXCERTO 4}

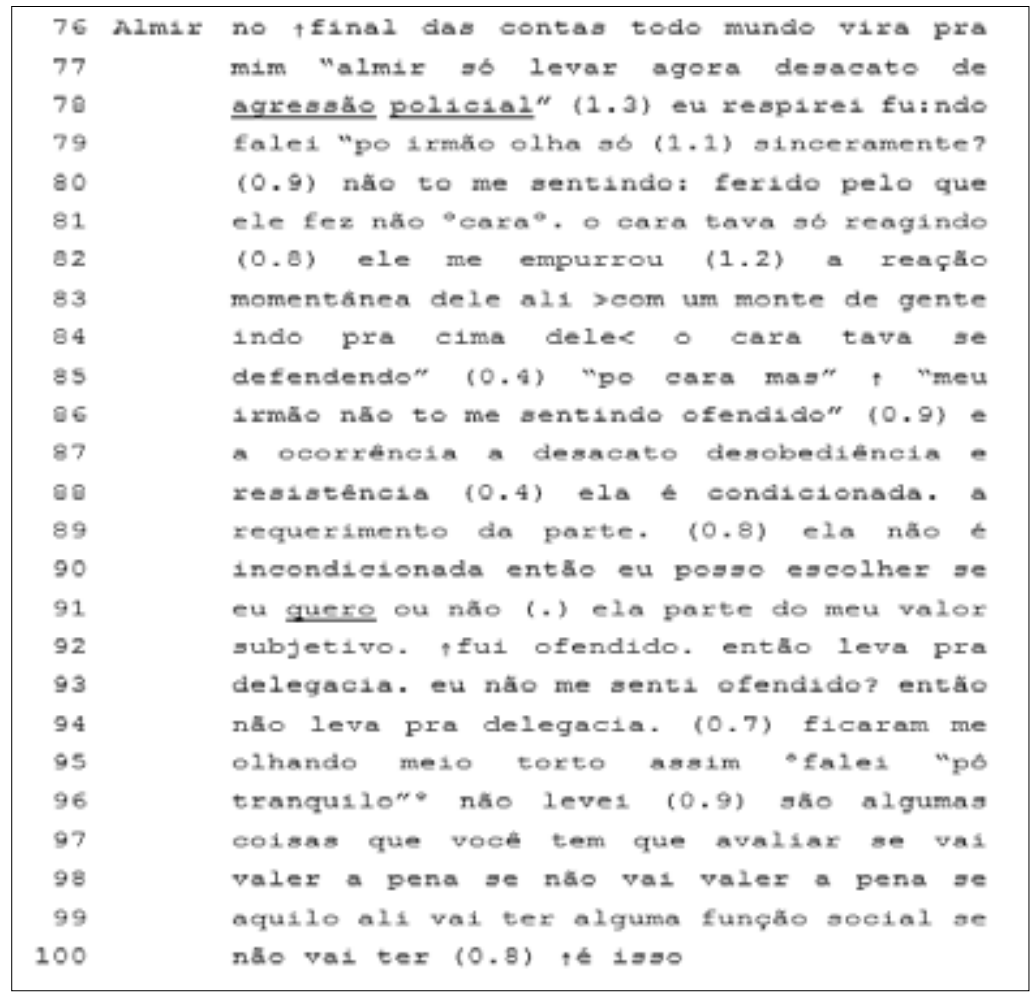


A resposta de Almir ao apelo dos policiais não é direta. Como em atos não preferidos (POMERANTZ, 1984), o narrador faz uma pausa antes de responder, o que é representado na narrativa pela informação "eu respirei fu:ndo" (linha 78). A pausa anuncia que a ação não preferida - no caso em questão, a rejeição da solução apresentada - está em curso. Dado que as ações desacato/condução à delegacia são um padrão de comportamento dos policiais, Almir se posiciona como quem precisa prestar contas (oferecer accounts nas 1. 79-85; 87-94) diante de seus pares para tomar sua decisão de não acolher o que foi proposto.

Em relação ao primeiro account, construído a partir de discurso direto, percebemos que Almir justifica a ação do vendedor pelas circunstâncias do evento. A seleção lexical apresenta relevância na construção do account. A utilização dos verbos "reagir" (1. 81) e "defender" (1. 85) nos leva a inferir que a primeira ação não partiu dele e que seu estado de nervosismo, conjugado à agressão que realiza, não ocorre sem justificativa. Na linha 82 o policial volta a formular a ação do vendedor não como agressão, mas como empurrão, mitigando mais uma vez a carga semântica de força do ato.

O segundo account complementa o primeiro na medida em que, mesmo que tentassem persuadi-lo a levar o ambulante à delegacia, o policial não pode ser obrigado a conduzir alguém se ele não se sentir desacatado. Portanto, por mais que os policiais pedissem, Almir não poderia/teria de fazê-lo por não avaliar as ações realizadas pelo ambulante como desacatos à sua autoridade policial. Ao dizer que possui direito de escolha em relação ao pedido de seus pares (1. 90-92), Almir expressa sua agência no processo de tomada de decisão discricionária ("eu posso escolher se eu quero ou não"). Segundo Muniz e Proença Júnior (2007, p. 41):

O poder de decidir sobre a ação policial mais adequada a um certo tipo de evento, ou mesmo de decidir agir ou não agir numa determinada situação diante de um evento ou de sua antecipação, revela que a tomada de decisão discricionária é a práxis essencial da polícia, do exercício do mandato policial.

Tal citação vai ao encontro da parte final da narrativa (1. 96100), quando Almir nos diz, em tom de lição de moral, que o policial (indeterminado pelo pronome "você") deve avaliar a função de suas ações. Há um entendimento de senso comum de que o policial apenas cumpre ordens, não reflete, apenas aplica as leis. 


\section{Considerações Finais}

Como se pôde observar com a análise dos excertos selecionados, mesmo em contextos altamente regulados, há sempre rotas de fuga que podem ser adotadas sem ferir normas ou regulamentos. No caso do contexto policial, uma das rotas está no exercício do princípio da discricionariedade nos processos decisórios, seja de uso da força, seja de decisões de julgamento de culpabilidade. Apesar de ser um princípio reconhecido pela instituição militar, a análise da narrativa torna possível observar que, na prática, o policial geralmente só reconhece uma rota de ação para todas as situações. A narrativa aqui estudada oferece a oportunidade de ver que há uma gama de escolhas possíveis circunscritas pela lei e pelos contextos de atuação.

A narrativa evidencia a complexidade do processo de tomada de decisão no calor dos acontecimentos. Além disso, nos mostra que, para servir à sociedade e construir relações de confiança com a população, é indispensável o exercício da agentividade no cumprimento da lei, com um posicionamento crítico e reflexivo quanto às formas de atuação, priorizando o respeito ao cidadão, mesmo quando esse infringe a lei.

\section{Agradecimentos}

Ao apoio financeiro do Conselho Nacional de Desenvolvimento Científico e Tecnológico (CNPq) à pesquisa "Expertise interacional e práticas profissionais" (processo 307806/2013-8), da qual uma das metas era o estudo da prática policial.

\section{Referências}

AHEARN, L. M. Agency. Journal of Linguistic Anthropology, Malden, v. 9, p. 12-15, 1999. DOI: https://doi.org/10.1525/jlin.1999.9.1-2.12

AHEARN, L. M. Language and agency. Annual Review of Anthropology, Palo Alto, v. 30, p. 109-137, 2001. DOI: https://doi.org/10.1146/annurev.anthro.30.1.109

AHEARN, L. M. Agency and language. In: JASPERS, J.; ÖSTMAN, J.; VERSCHEREN, J. (Ed.). Society and language use. Amsterdam: John Benjamins, 2010. p. 28-48. (Handbook of Pragmatics Highlights, vol. 7).

BAMBERG, M.; GEORGAKOPOULOU, A. Small stories as a new perspective in narrative and identity analysis. Text \& Talk, London, v. 28, n. 3, p. 377-396, 2008. DOI: https://doi.org/10.1515/TEXT.2008.018 
BETINI, E. M.; DUARTE, C. T. S. Curso de uso diferenciado da força. São Paulo: Ícone, 2012.

BUCHOLTZ, M.; HALL, K. Identity and interaction: a sociocultural linguistic approach. Discourse Studies, London, v. 7, p. 585-614, 2005. DOI: https://doi. org/10.1177/1461445605054407

DURANTI, A. Agency in language. In: DURANTI, A. (Ed.). A companion to linguistic anthropology. Massachusetts: Blackwell, 2004. p. 451-473.

FONTANA, A.; FREY, J. H. The interview: from neutral stance to political involvement. In: DENZIN, N. K.; LINCOLN, Y. S. (Ed.). The SAGE bandbook of qualitative research. Thousand Oaks: SAGE, 2005. p. 695-727.

FOUCAULT, M. História da sexualidade I: a vontade de saber. Rio de Janeiro: Graal, 1999.

GAGO, P. C. Questões de transcrição em análise da conversa. Veredas, Juiz de Fora, v. 6, n. 2, p. 89-113, 2002.

GARCEZ, P. M.; BULLA, G. S.; LODER, L. L. Práticas de pesquisa microetnográfica: geração, segmentação e transcrição de dados audiovisuais como procedimentos analíticos plenos. Delta, São Paulo, v. 30, n. 2, p. 257-288, 2014. DOI: https://doi.org/10.1590/0102-445078307364908145

GIDDENS, A. The constitution of society. Cambridge: Polity, 1984.

KLOCKARS, C. B. The idea of police. London: Sage, 1985.

LABOV, W. The transformation of experience in narrative syntax. In: LABOV, W. Language in the inner city. Philadelphia: University of Pennsylvania Press, 1972. p. 354-397.

MENEZES, P. V. Entre o "fogo cruzado" e o "campo minado": uma etnografia do processo de "pacificação" de favelas cariocas. 2015. 416 f. Tese (Doutorado em Sociologia) - Universidade do Estado do Rio de Janeiro, Rio de Janeiro, 2015.

MUNIZ, J. "Ser policial é, sobretudo, uma razão de ser": cultura e cotidiano da Polícia Militar do Estado do Rio de Janeiro. 1999. 285 f. Tese (Doutorado em Ciência Política) - Instituto Universitário de Pesquisas do Rio de Janeiro, Rio de Janeiro, 1999.

MUNIZ, J. Discricionariedade policial e a aplicação seletiva da lei na democracia. 2008. Disponível em: < https://goo.gl/wGCdex>. Acesso em: 14 jan. 2017.

MUNIZ, J.; PROENÇA JÚNIOR, D. Da accountability seletiva à plena responsabilidade policial. In: CARUSO, H.; MUNIZ, J.; BLANCO, A. C. C. (Org.). Polícia, Estado e sociedade: práticas e saberes latino-americanos. Rio de Janeiro: Publit, 2007. p. 21-73. 
POMERANTZ, A. Agreeing and disagreeing with assessments: some features of preferred and dispreferred turn shaped. In: ATKINSON, J. M.; HERITAGE, J. (Ed.). Structures of social action. Cambridge: Cambridge University Press, 1984. p. 57-101.

PONCIONI, P. O modelo policial profissional e a formação profissional do futuro policial nas academias de polícia do estado do Rio de Janeiro. Sociedade e Estado, Brasilia, DF, v. 20, n. 3, p. 585-610, 2005. DOI: https://doi.org/10.1590/S010269922005000300005

RIESSMAN, C. K. Narrative analysis. Thousand Oaks: SAGE, 1993.

RYMES, B. The construction of moral agency in the narratives of high-school dropouts. Discourse \& Society, London, v. 6, n. 4, p. 495-516, 1995. DOI: https:// doi.org/10.1177/0957926595006004003

SACKS, H. Lectures on conversation. Oxford: Blackwell, 1992.

SACKS, H.; SCHEGLOFF, E. A.; JEFFERSON, G. Sistemática elementar para a organização da tomada de turnos para a conversa. Veredas, Juiz de Fora, v. 7, n. 1-2, p. 9-73, 2003.

TANNEN, D. Talking voices: repetition, dialogue, and imagery in conversational discourse. Cambridge: Cambridge University Press, 2007. DOI: https://doi. org/10.1017/CBO9780511618987

TANNEN, D.; WALLAT, C. Enquadres interativos e esquemas de conhecimento em interação. Exemplos de um exame/consulta médica. In: RIBEIRO, B. T.; GARCEZ, P. M. (Org.). Sociolinguística interacional. São Paulo: Loyola, 2013. p. 183214.

VELASCO, A. D. B. Ninguém gosta de policial: o discurso de policiais de uma Unidade de Polícia Pacificadora e seus recursos retóricos. 2014. 75 f. Dissertação (Mestrado em Letras/Estudos da Linguagem) - Pontifícia Universidade Católica do Rio de Janeiro, Rio de Janeiro, 2014.

VELASCO, A. D. B.; OLIVEIRA, M. C. L. Sorria: você está sendo filmado. A espetacularização da prática policial e o trabalho de limpeza moral. Gragoatá, Niterói, v. 21, n. 40, p. 380-398, 2016.

WATSON, D. R. Categorization, authorization and blame-negotiation in conversation. Sociology, v. 12, n. 1, p. 105-113, 1978. DOI: https://doi. org $/ 10.1177 / 003803857801200106$ 


\section{ANEXO 1}

\section{Convenções de Transcrição}

\begin{tabular}{|l|l|}
\hline$(0.5)$ & Pausa em décimos de segundo \\
\hline$()$. & Micropausa de menos de dois décimos de segundo \\
\hline$[$ colchetes $]$ & Fala sobreposta \\
\hline$=$ & Contiguidade entre a fala de um mesmo falante ou de dois falantes distintos \\
\hline$\cdot$ & entonação descendente ou final de elocução \\
\hline$?$ & entonação ascendente \\
\hline, & entonação de continuidade \\
\hline$\uparrow$ & subida de entonação \\
\hline$\downarrow$ & descida de entonação \\
\hline- & Autointerrupção \\
\hline sublinhado & Énfase \\
\hline MAIÚSCULA & Fala em voz alta ou muita ênfase \\
\hline opalavra & Palavra em voz baixa \\
\hline$>$ palavra< & Fala mais rápida \\
\hline$<$ palavra $>$ & fala mais lenta \\
\hline$:$ ou :: & alongamentos \\
\hline() & fala não compreendida \\
\hline$(())$ & comentário do analista, descrição de atividade não verbal \\
\hline “palavra” & fala relatada, reconstrução de um diálogo \\
\hline hh & aspiração ou riso \\
\hline
\end{tabular}

Convenções baseadas em Sacks, Schegloff e Jefferson (2003) com incorporação de símbolos sugeridos por Tannen (2007). 
